\title{
The Research about Factors and Countermeasures of Influence Changsha-Zhuzhou-Xiangtan Urban Agglomeration Development of Public Sports Service in China*
}

\author{
Luojing Zhu' ${ }^{1}$, Xinsen $\mathrm{He}^{2}$ \\ ${ }^{1}$ The Department of P.E. of Central South University of Forestry and Technology, Changsha, China; ${ }^{2}$ The Department of P.E. of \\ Nanchang Institute University, Nanchang, China. \\ Email: zhulj97@sina.com.cn, pockman@tom.com
}

Received July, 2013

\begin{abstract}
The paper analyzed the Changsha-Zhuzhou-Xiangtan urban agglomeration sports public service in China. There are many influence factors about Changsha-Zhuzhou-Xiangtan urban agglomeration sports public service. As follows: 1) The complexity of Administrative districts restricted balance development of the sports public services in the Changsha-Zhuzhou-Xiangtan urban agglomeration; 2) Dual economic structure of urban and rural areas result in imbalance of city and countryside development; 3) The single outlay source of sports funds has restricted the development and affected the increase of quality of sports public service. At the same time, I put forward the corresponding countermeasures and Suggestions: 1)T Choose compound administration model to be administrative model of Changsha-Zhuzhou-Xiangtan urban agglomeration; 2) Promoting urban and rural integration to realize equalization of sports public service; 3) Improving sports public service system of the community; 4) Actively exploring multi-channel financing of sports and optimizing sports funds structure; 5) Establishing fairly detailed Assessment system associated with sports public service.
\end{abstract}

Keywords: Urban Agglomeration; Public Sports Service; Development

\section{Introduction}

Sports public service system is the one of the important parts of the public service system. As the provider of public social product, the government should meet the public service of public sports wants to conform to the trend of social development. The government has a responsibility for building the public sports service system [1]. "Sports public service" is made of sports and public service. "public sports service" has two kinds of structure as follows: "public + sports service" and "public sports + service". "public sports + service" responds to "private sports + service". The former highlights the service of the public sports field [2]. However, this paper refers to the sports public service. Constructing Changsha-ZhuzhouXiangtan urban agglomeration sports public service system can promote the health of people, improve people's quality of life, cut down medical cost and develop human resources power.

\footnotetext{
${ }^{*}$ The fund of Hunan Province Department of Education in 2010. Fund code:10C1341
}

\section{The Situation of the Core City Sports Public Service Resources of Changsha-Zhuzhou-Xiangtan Urban Agglomeration}

There are three aspects to measure sports public service as follows: the funds of sports for all, public sports facilities and the number of social sports instructor per million people. Because there are not special statistics of the funds of sports for all from the national statistics bureau to local statistics bureau, we can not ascertain specific circumstance about the funds of sports for all. but we could roughly estimate the number of the funds of sports for all by some basic data. (The related statistical data involves the number of employees, the situation of break world records and international sports communication)(Table 1)

As is shown by the figure in the table 1 , the proportion of sports in the GDP of Changsha-Zhuzhou-Xiangtan urban agglomeration is low. Even the official figures of the national economic and social development of Xiangtan 
Table 1. The statistical data of sports resource of Changsha, Zhuzhou, Xiangtan and China[3-7].

\begin{tabular}{|c|c|c|c|c|}
\hline & $\begin{array}{l}\text { Changsha } \\
\text { (RMB } 1 \text { billion) }\end{array}$ & $\begin{array}{l}\text { Zhuzhou } \\
\text { (RMB } 1 \text { billion) }\end{array}$ & $\begin{array}{l}\text { Xiangtan } \\
\text { (RMB } 1 \text { billion) }\end{array}$ & China(RMB 1 billion) \\
\hline GDP in 2010 (1 billion RMB) & 454.70 & 127.48 & 89.40 & 39798.30 \\
\hline $\begin{array}{l}\text { Gross output of sports,culture and } \\
\text { health in } 2010 \text { ( } 1 \text { billion RMB) }\end{array}$ & 38.71 & nullinformation & nullinformation & 2596 \\
\hline $\begin{array}{l}\text { Sports, culture and health accounts } \\
\text { for the proportion of GDP } \\
\text { in the corresponding city }\end{array}$ & $0.85 \%$ & nullinformation & nullinformation & $\begin{array}{l}0.3 \% \text { (sports production } \\
\text { value accounts for the } \\
\text { proportion of GDP) }\end{array}$ \\
\hline $\begin{array}{l}\text { The number of public } \\
\text { sports facilities }\end{array}$ & $\begin{array}{l}766 \text { Fitness guidance } \\
\text { stations, } 470 \text { public } \\
\text { sports facilities }\end{array}$ & $\begin{array}{l}1319 \text { sports facilities, } \\
\text { involving15 gym,204 } \\
\text { sports ground and } 18 \\
\text { swimming pools,etc. }\end{array}$ & $\begin{array}{l}\text { More than } 1500 \text { public } \\
\text { sports facilities, } \\
1,060,000 \mathrm{~m}^{2} \\
\text { sports venue area }\end{array}$ & $\begin{array}{l}\text { More than } 850,000 \\
\text { sports facilities }\end{array}$ \\
\hline $\begin{array}{l}\text { Per capita sports venues } \\
\left(\mathrm{m}^{2} / \text { person }\right)\end{array}$ & 1.20 & 1.20 & 1.49 & $\begin{array}{l}1.03 \\
\text { (the data of } 2009 \text { year) }\end{array}$ \\
\hline $\begin{array}{l}\text { the Number of Social } \\
\text { Sports Instructor }\end{array}$ & 7750 & nullinformation & 2600 & 700,000 \\
\hline $\begin{array}{l}\text { the Number of Social } \\
\text { Sports Instructor per 1,000,000 }\end{array}$ & 11 & nullinformation & 9.50 & 5.40 \\
\hline
\end{tabular}

city and Zhuzhou city are not reflects the ratio of the culture, physical education and health to GDP in 2010. We could roughly estimate that the proportion of sports in the Changsha city's GDP are less than $0.85 \%$ considering the proportion of culture, sports and health, which account for $0.85 \%$ of Changsha city's GDP in 2010.

The proportion of sports industry is very small in the whole country level. Sports production value is only $0.7 \%$ of GDP in China. However, sports production value is $11 \%$ of GDP in the United States. There are significant difference between China and U.S.

\section{The Factors of Influence Development Public Sports Service of Changsha-Zhuzhou-Xiangtan Urban Agglomeration}

\subsection{The Complexity of Administrative Districts Restricted Balance Development of the Sports Public Services in the Changsha-Zhuzhou-Xiangtan Urban Agglomeration}

The administrative division of Chang sha-Zhuzhou-Xiang tan urban agglomeration involved Zhuzhou, Xiangtan, Changsha, Yueyang, Changde, Yiyang, Loudi, Hengyang, etc. Administrative districts area is large. At present administrative organization reform of Changsha-ZhuzhouXiangtan urban agglomeration is brewing. The sports administrative institution reform doesn't respond to that. Governments should establish unified sports administrative agencies of Changsha-Zhuzhou-Xiangtan urban agglomeration to integrate all sports public service re- sources and promote equalization of sports public service.

\subsection{Dual Economic Structure of Urban and Ru- ral Areas Result in Imbalance of City and Countryside Development}

Changsha-Zhuzhou-Xiangtan urban agglomeration is becoming "National Experimental Area of Comprehensive Reform Package of Resource Conserving and Environmental friendly Social Construction" through approval, which explore endogenous economic development road, establish endogenous development mode suitable for China's national conditions and promote the rise of Central China,by taking advantages of energy, rich labor force resource, dense population and great market potential. However, dual economic structure of urban and rural areas result in imbalance of city and countryside development [8].

\subsection{The Single Outlay Source of Sports Funds Has Restricted the Development and Affected the Increase of Quality of Sports Public Service}

At present the source of sports funds of Changsha-Zhuzhou-Xiangtan urban agglomeration is single and inadequate. Government input and public welfare fund from sports lottery are main source of sports public service. In the way of government input there are different among Changsha, Xiangtan and Zhuzhou because of the difference of three municipal government financial revenue input. The sports financial expenditure 3 cities in 2010 as 
follows:

1) The government input of cultural, sports and mass media of Changsha city were 0.24 billion RMB in 2010[9]. 2) There were no show use of sports funds in 2010 budget performance document of Xiangtan city municipal government. 3) There were not single out use of sports funds in 2010 budget performance document of Zhuzhou city municipal government. As is indicated in the document that aggregate financial expenditure involving education, agriculture, social security, job, health, environmental protection, culture and sports were 10.58 billion RMB [10].

Furthermore, the sport for all input of Hunan provincial government were 43.01 million RMB in 2010 [11].

Above all, there are some features in the way of government input about sports public service as follows: 1) There were not single out the expenditure of sports public service in the financial expenditure of 3 municipal government. Even the expenditure of sports was not exist in the financial expenditure of Xiangtan municipal government. 2) The proportion of sport for all is too small in the whole sports expenditure. 3) The yearly average basic sport for all funds standard is shortcut. As is shown in "2006-2010 years sports development plan of Changsha city" that the yearly average basic sport for all funds were $0.2 \mathrm{RMB}$ in 2010.

\section{Recommendation}

\subsection{Choose Compound Administration Model to Be Administrative Model of Changsha-Zhuzhou-Xiangtan Urban Agglomeration}

The compound administration model is a cooperative mechanism, which is realize the goal of public service sharing across administrative districts and administrative level between the government for promoting regional economic integration. In addition, the compound administration model needs government participation[12]. The main problem of public administration of Changsha-Zhuzhou-Xiangtan urban agglomeration is boundary conflict between administrative region and economic zone. The border of administrative region is tangible and rigid. but the boundary of economic zone is invisible and elastic." The tangible administrative region" shall restrict the development of economic zone.

The administration model of sport public service of Changsha-Zhuzhou-Xiangtan urban agglomeration should adopt compound administration model. At the same time,

There is a very important meaning for local government's institutional innovation under the idea of compound administration. It is demand of socialist market economy developing, socialist harmonious society constructing and civil society growing. Government should focus on sport for all rather than competitive sports.

\subsection{Promoting Urban and Rural Integration to Realize Equalization of Sports Public Service}

Equalization of sports public service is not simple meaning for everyone to get the same sports public service. It includes two implications as follows: On the one hand, reasonable distribution of public sports service resources is based on population density. On the other hand, all citizens will have access to basic public service of equal opportunity and the approximate results. The government should respect free option of society members [13]. The problem of the urban and rural dual structure can not be soluted through abolishing the system of agricultural registered permanent residence in China. Developing economic foundation is the root of problem. Futhermore, the reasonable adjustment of industrial structure and the corresponding system reform are keys.

\subsection{Improving Sports Public Service System of the Community}

The development trend of China's urban is the community becoming the basic component of urban development unit in the future. Taking the community as the basic units can effectively and reasonably configurate basic sports public resources. Although there is a large population flow in cities, the population flow of community will be relatively stable relative to the population flow of the whole city. It can make up for shortage of the sports field resource in cities through making full use of the square, park, school sports facilities in the community. Although at the current stage opening school facilities will confront some management risk such as how to obtain sufficient maintenance funds of sports facilities, in the long run it is the development trend when the urban land resource is nervous.

\subsection{Actively Exploring Multi-channel Financing of Sports and Optimizing Sports Funds Structure}

Sports public service of government input is more abundant than in the past in China. But it still has its shortcomings as follows: Low administrative efficiency, quality sports product and public service, etc. Under The Circumstance of market economy, government couldn't provide as enough sports public service as it was in planned economy era in China[14]. Therefore, on the one hand, government should encourage private capital enter the domain of sports public service. At the same time, 
sports administrations have responsibility for supervising private enterprise. On the other hand, it is a useful way forward that government gradually increase sports budget, and increase sport for all funds proportion for optimizing funds structure in view of immense business value of competitive sports.

\subsection{Establishing Fairly Detailed Assessment System Associated with Sports Public Service}

Now government doesn't establish fairly detailed Assessment system associated with sports public service. There are a few researches about Assessment system of sports public services in academic community. But research achievement is few. There are many differences with economy and culture of every city, so there are also differences with the evaluation index and evaluation method about sports public services among cities. Even so, it is important that government establish sports public service evaluation system. The evaluation system of sports public service will be one of necessary system of urban management in the future.

\section{Concluding Remarks}

Chinese government pays more and more attention to the livelihood of people. With the rapid development of economy in Changsha-Zhuzhou-Xiangtan urban agglomeration, an increasing number of people come to realize that Perfecting public service system is key way of improving the livelihood of people. Sports public service is an integral part of public service system. In the meantime, Perfecting sports public service system is a gradual process.

\section{REFERENCES}

[1] X. L. Pen, L. Z. Hao and Y. X. Cheng, "Development of Public Sport Service System and Its Structure in China,” Journal of Tianjin University of Sport, Vol. 22, 2007, pp. 472.

[2] D. Y. Fan, "Several Issues in the Research on Chinese Sports Public Service,” Journal of Chengdu University of sport, Vol. 2, 2010, p. 7.

[3] Official Website of Administration of Sports of Xiangtan Municipality, Performance assessment summary Administration of Sports of Xiangtan Municipality in 2010, Available from. http://ty.xiangtan.gov.cn/html/xttyj/zhsx/2011/523203229 .html, May 2011.
[4] Official Website of Changsha Statistical Bureau, The National Economy and Social Development Statistical Bulletin of Changsha City in 2010, Available from. http://www.cstj.gov.cn/ndcss/20110323/15586.html, March 2011.

[5] Chinese Statistics Web Links, The National Economy and Social Development Statistical Bulletin of Zhuzhou City in 2010. Available from.

http://www.tjcn.org/plus/view.php?aid=19015, March 2011.

[6] Statistical Information of Hunan, The National Economy and Social Development Statistical Bulletin of Zhuzhou City in 2010. Available from.

http://www.hntj.gov.cn/tjgb/szgb/201103/t20110315_834 03.html, March 2011.

[7] The Central People's Government of the People’s Republic of China, The National Economy and Social Development Statistical Bulletin in 2010. Available from. http://www.gov.cn/gzdt/2011-02/28/content_1812697.ht ml, February 2011.

[8] T. Ou Yang and P. Xiang, "Discussion about Planning Urban City and Rural Areas Development as a Whole in Two Types of Society Construction in CHANGZHUTAN," Chinese Journal of Agricultural Rrsources and Regional Planning, 2008, p. 41.

[9] Changsha Municipal People's Government, Changsha Government Reports about Implementation of the Budget and Drafted Budget at the Corresponding Level in 2010. Available from.

http://www.changsha.gov.cn/xxgk/szfxxgkml/czxx/czyjs/ 201105/t20110512_11071.html, 2011.

[10] Zhuzhou Official Website, Zhuzhou Government reports about implementation of the budget in 2010 and drafted budget at the corresponding level in 2011.Available from. http://www.hunanzhuzhou.gov.cn/sitepublish/site1/gov/cz ss/czyjc/content_143746.html, 2011.

[11] Official Website of Administration of Sports of Hunan Province, The Bulletin about Hunan Province Service Condition of Welfare Lottery in 2010. Available from. http://www.sports.gov.cn/hnnews/wuda/gonggao/201161 0110952.html, 2011.

[12] S. Liu and C. L. Deng, "Compound Administration: The Middle Regional Management Model in China," Chinese Public Administration, Vol. 1, 2008, pp. 85-86.

[13] X. P. Qin, J. Wang and C. F. Lu, "Opinions on the Issue of Realizing the Equalization of Basic Public Sports Services in China," Journal of Physical Education, pp. 33, 2009.

[14] X. Qian, "Feasibility of and Approaches to Nongovernmental Supply of Public Sports Products," Journal of Physical Education, Vol. 4, 2005, pp. 128-130. 